\title{
Status of Psychological Capital of Students in Kurdistan University of Medical Sciences
}

\section{A R T I C L E I N F O}

\section{Article Type}

Descriptive Study

\section{Authors}

Rezaei Z. ${ }^{1} M S C$

Vahabi A. ${ }^{2} P h D$,

Karimianpour Gh.* $M S C$

Latifi $A^{3} P h D$,

Ramezani Sh. ${ }^{4} \mathrm{MSC}$,

Nouri E. ${ }^{5} B S C$,

Moradi M. ${ }^{6} M S C$

\section{How to cite this article}

Rezaei Z, Vahabi A, Karimianpour

Gh, Latifi A, Ramezani Sh, Nouri E,

Moradi M. Status of Psychologic-

al Capital of Students in Kurdist-

an University of Medical Scien-

ces. Health Education and Health

Pr-omotion. 2018;6(2):53-58.

*Educational Sciences Department, Education \& Psychology Faculty, University of Mohaghegh Ardabili, Ardebil, Iran

${ }^{1}$ Students Research Committee, Kurdistan University of Medical Sciences, Sanandaj, Iran

2Medical Laboratory Sciences Department, Paramedicine Faculty, Kurdistan University of Medical Sciences, Sanandaj, Iran

${ }^{3}$ Public Health Department, Public Health Faculty, Maragheh University of Medical Sciences, Maragheh, Iran ${ }^{4}$ Educational Sciences Department, Education \& Psychology Faculty, Kamyaran Branch, Payam-e-noor University, Kamyaran, Iran

${ }^{5}$ Public Health Department, Public Health Faculty, Kurdistan University of Medical Sciences, Sanandaj, Iran ${ }^{6}$ Research \& Technology Deputy, Kurdistan University of Medical Sciences, Sanandaj, Iran

\section{Correspondence}

Address: Educational Sciences Department, Education \& Psychology Faculty, University of Mohaghegh Ardabili, Daneshgah Street, Ardebil, Iran. Postal Code: 5619911367 Phone: -

Fax: -

karimiangh@gmail.com

\section{Article History}

Received: August 30, 2017

Accepted: January 30, 2018

ePublished: April 30, 2018

\section{A B S T R A C T}

Aims The psychological capital is one of the important indicators of positive psychology and it has positive outcomes for students. The present research aimed at studying the status of psychological capital of students in Kurdistan University of Medical Sciences and its related factors.

Instruments \& Methods The present descriptive-analytical cross sectional research was conducted among 384 students in Kurdistan University of Medical Sciences in 2016. The samples were selected by simple random sampling method. Luthans et al.'s psychological capital questionnaire was employed for the data collection and data analysis was performed, using SPSS 22 software by descriptive statistics (mean and standard deviation) and inferential statistics (Mann-Whitney U test and Kruskal-Wallis test).

Findings A total of 150 participants (39.2\%) were male and 233 (60.8\%) were female; 351 participants (91.6\%) were single and $32(8.4 \%)$ were married. The mean score of the psychological capital of students was 89.09 \pm 9.98 . Minimum and maximum means were measured for Optimism and Self-efficacy. There was a significant relationship between sex, field of study, academic degree, and faculty place with psychological capital $(\mathrm{p}<0.05)$.

Conclusion Factors such as sex, field of study, academic degree, and faculty place are effective in the psychological capital of students.

\section{Keywords Resilience Psychological; Students; Medical Sciences}

\section{I T A T I O N L I N K S}

[1] The relationship between psychological capital and organizational commitment components [2] Psychological capital and intraprunership among faculty members [3] Positive psychology: An introduction. Am Psychol [4] Psychological capital development: Toward a micro-intervention [5] Emerging positive organizational behavior [6] Relationship of core self-evaluations traits--self-esteem, generalized self-efficacy, locus of control, and emotional stability--with job satisfaction and job performance: A metaanalysis [7] Self-efficacy: Toward a unifying theory of behavioral change [8] Hope and optimism as related to life satisfaction [9] Learned optimism: How to change your mind and your life [10] Fostering children's resilience [11] Competence and resilience in development [12] The relationship of psychological capital (hope, optimism, resiliency and self-efficacy) with the achievement goals and academic performance of the firstyear students [13] Predictor factors of psychological well-being in students [14] The role of psychological capital on social capital of physical education students of Mashhad universities [15] The socio-demographic correlations of psychological capital [16] Psychological capital, work engagement and organisational commitment amongst call centre employees in South Africa [17] The relationship between psychological capital and spiritual intelligence with vitality of Urmia University students [18] Investigating the relationship between demographic characteristics and psychological capital of teachers (Case study: Primary school teachers in Isfahan city) [19] The relationship between psychological capital in personnel work setting with their work flow and engagement in the organization 


\section{Introduction}

Psychological capital is one of indicators in positive psychology and it is defined as believing in individual abilities for reaching success, working hard for following the goals, creating positive documents, and tolerating difficulties [1]. It is a new concept in the organized behavior literature and roots in Seligman's positive psychological movement $[2,3]$. The positive evaluation of this situation and reaching success based on motivationoriented effort and hard work are known as psychological capital [4]. Psychological capital means "who are you" (the real ego) and "who are you going to be" (possible ego) on a developmental and growing basis [5]. In fact, psychological capital is a composite and continuous construct [6].

This variable includes self-efficacy, hope, optimism, and resiliency. Self-efficacy is defined as a strong belief in individual's capabilities for equipping motivational and cognitive sources as well as strategies required for successful implementation of certain tasks in the given situations [7]. Hope component is a cognitive situation or a thought that makes people able to frame real, challenging, and predictable goals. Then, they will reach such goals by will, energy, and internalized control perception [8]. Optimism is defined as an interpretational style that attributes positive events to permanent, personal, and pervasive causes as well as negative events to external, temporal causes, and given conditions [9]. And, resiliency is a psychological capacity, by which individuals can successfully cope with change, crisis, risk, and problems) $[4,10,11]$.

Such components give meaning to the individual's life via an interactive and evaluative process, increase individual's effort to change stressful situations, prepare the individual to face the real world, as well as ensure individual's resiliency for realization of the goals [6].

Many research studies have been carried out on psychological capital and its positive outcomes [12, 13]. The results of a study conducted by Mohebi et al. showed that the mean psychological capital of students is 166.55 and there is a positive and significant relationship between psychological capital and goals of academic achievement and performance [12]. Shakarami et al.'s study indicated that the mean psychological capital of students is 96.54 and psychological capital is one of the predictor variables of psychological well-being and it explores 37\% of changes related to psychological well-being [13].

Nowadays, students face many pressures during academic years. Therefore, they should have essential ability and skill to cope with such pressures. On the other hand, unemployment after graduation can make different reactions in students. Students with high psychological capital experience low stress in academic setting. They may see positive factors, which empower them. For example, an optimistic, hopeful, self-efficient individual may believe that $\mathrm{s} /$ he has sufficient sources to avoid failure in a stressful condition; thus, s/he experiences low stress. Generally, students with high psychological capital will resist against high stress [13].

Concerning the role of psychological capital in the increasing academic performance of students in universities and in individual's life in general, the present research aimed at studying the status of psychological capital of students in Kurdistan University of Medical Sciences and its related factors.

\section{Instruments and Methods}

The present descriptive-analytical cross sectional study was conducted among all students in Kurdistan University of Medical Sciences in 2016. The samples were selected by simple random sampling method. The sample size was estimated 383 individuals, using Cochran formula in terms of 5\% error. Since some students might not fill the questionnaires, $10 \%$ of samples were added as drop out; thus, 420 samples were considered.

Luthans et al.'s psychological capital questionnaire was used to measure psychological capital [4]. This questionnaire includes 2 parts of demographic questions (age, sex, academic degree, the place of faculty, and marital status) and 24 main questions under 4 subscales of self-efficacy (items 1-6), hope (items 7-12), optimism (items 13-18), and resiliency (items 19-24). The questions were answered based on the five-point Likert scale. Content validity of the questionnaire was confirmed by experts and its reliability was reported 0.77 in a research 
carried out by Hoveida et al., using Cronbach alpha coefficient [1].

For data collection from the studied faculties, the researchers went to the selected classes. Before the study, explanations were provided to the students about the importance of the study. We requested the samples to complete the questionnaires carefully. Participation in the study was optional for the students, and they were not forced to do this. They did not need to write their names and other identifiable specifications.

The data were analyzed, using SPSS 22 software by descriptive (mean, standard deviation, and frequency) and inferential statistics (Mann-Whitney U test and Kruskal Wallis test).

\section{Findings}

Out of the 383 subjects, 150 (39.2\%) were male and 233 (60.8\%) were female. Most subjects were between 20 and 22 years old (38.6\%); 351 subjects were single (91.6\%) and 32 subjects were married (8.4\%) and 307 subjects were undergraduates (80.2\%). Most subjects were studying in paramedical faculty $(32.4 \%)$ and the lowest number of students was associated with faculty of dentistry (5.0\%). In addition, some of the students were studying in the field of medical sciences; the lowest number of students was associated with studying in M.S and midwifery fields $(5.0 \%)$.

The mean score of psychology was $89.09 \pm 9.98$ out of total 120 scores. The highest score and the lowest score were obtained by selfefficacy and optimism, respectively (Table 1).

Table 1) Limits, mean, and standard deviation of psychological capital and its subscales

\begin{tabular}{lccc}
\hline \multicolumn{1}{c}{ Components } & $\begin{array}{c}\text { Possible } \\
\text { range }\end{array}$ & $\begin{array}{c}\text { View } \\
\text { range }\end{array}$ & Mean \pm SD \\
\hline Self-efficacy & $6-30$ & $9-30$ & $23.48 \pm 3.29$ \\
Hope & $6-30$ & $7-30$ & $22.11 \pm 5.12$ \\
Optimism & $6-30$ & $10-30$ & $21.63 \pm 3.22$ \\
Resiliency & $6-30$ & $8-30$ & $22.41 \pm 4.32$ \\
Psychological capital & $24-120$ & $57-112$ & $89.09 \pm 9.98$ \\
\hline
\end{tabular}

There was a significant relationship between sex and total score of psychological capital $(p \leq 0.05)$ and the mean score of psychological capital in male students was more than that in female students. Furthermore, the mean score of subscales of psychological capital in male students was more than that in female students expect for optimism. Such difference was statistically significant in self-efficacy and hope $(p \leq 0.05)$. Moreover, the total score of psychological capital and its subscales in married individuals was more than that of single individuals, but such difference was not statistically significant ( $p>0.05$; Table 2).

Table 2) The mean \pm SD of psychological capital and its subscales in terms of sex and marital status

\begin{tabular}{lccccc}
\hline \multicolumn{1}{c}{ Group } & Self-efficacy & Hope & Optimism & Resiliency & Psychological capital \\
\hline Sex & & & & & \\
Male & $23.72 \pm 3.38$ & $22.62 \pm 2.70$ & $21.56 \pm 2.71$ & $22.42 \pm 2.66$ & $90.34 \pm 8.41$ \\
Female & $23.33 \pm 3.23$ & $21.43 \pm 4.22$ & $21.67 \pm 3.52$ & $21.85 \pm 3.53$ & $88.30 \pm 10.82$ \\
Marital status & & & & & \\
Married & $24.18 \pm 2.57$ & $22.68 \pm 2.88$ & $22.34 \pm 4.78$ & $22.09 \pm 3.16$ & $91.06 \pm 9.49$ \\
Single & $23.41 \pm 2.57$ & $21.83 \pm 3.80$ & $21.56 \pm 3.07$ & $21.84 \pm 3.88$ & $88.92 \pm 10.02$ \\
\hline
\end{tabular}

The total score of psychological capital was the highest in under 20-year-old individuals, but there was no significant difference between age groups ( $p>0.05)$. In addition, there was a statistically significant difference among subscales of psychological capital in age groups as well as between self-efficacy and optimism $(\mathrm{p}<0.05)$.

The total score of psychological capital and its subscales was more in Ph.D. candidates than other students. Such difference was statistically significant in self-efficacy and optimism subscales ( $\mathrm{p}<0.05$; Table 3 ).

Furthermore, there was a significant relationship between faculty place of students, the total score of psychological capital, and its subscales $(\mathrm{p}<0.05)$. The students of medical faculty obtained the highest score of psychological capital with the mean and standard deviation of $94.36 \pm 7.87$ and students of health faculty obtained the lowest mean score of psychological capital with the mean and standard deviation of $87.14 \pm 10.69$ (Table 3). 
Table 3) The mean \pm SD of psychological capital and its subscales in terms of age groups,

\begin{tabular}{|c|c|c|c|c|c|}
\hline Variables & Self-efficacy & Hope & Optimism & Resiliency & Psychological capital \\
\hline \multicolumn{6}{|l|}{ Age } \\
\hline Under 20 & $23.66 \pm 2.90$ & $22.27 \pm 3.41$ & $22.40 \pm 3.59$ & $22.02 \pm 3.53$ & $90.37 \pm 10.85$ \\
\hline $20-22$ & $23.41 \pm 2.96$ & $21.38 . \pm 4.07$ & $21.18 \pm 3.01$ & $21.85 \pm 3.54$ & $88.46 \pm 9.86$ \\
\hline $23-25$ & $21.22 \pm 4.61$ & $22.25 \pm 3.68$ & $21.16 \pm 3.20$ & $22.14 \pm 2.90$ & $89.37 \pm 9.86$ \\
\hline Over 25 & $21.22 \pm 3.54$ & $21.90 \pm 2.24$ & $21.09 \pm 3.16$ & $23.31 \pm 1.46$ & $87.54 \pm 9.97$ \\
\hline \multicolumn{6}{|l|}{ Academic degree } \\
\hline B.S. & $23.25 \pm 3.13$ & $21.65 \pm 3.93$ & $21.56 \pm 3.33$ & $22.03 \pm 3.41$ & $88.50 \pm 10.22$ \\
\hline M.Sc. & $20.90 \pm 3.75$ & $21.85 \pm 2.32$ & $21.25 \pm 2.31$ & $21.95 \pm 1.53$ & $85.95 \pm 8.16$ \\
\hline Ph.D. & $25.67 \pm 2.86$ & $23.30 \pm 2.64$ & $22.16 \pm 2.83$ & $22.33 \pm 2.55$ & $93.48 \pm 7.91$ \\
\hline \multicolumn{6}{|l|}{ Faculty place } \\
\hline Medicine & $25.68 \pm 3.09$ & $23.57 \pm 2.80$ & $23.00 \pm 2.46$ & $22.59 \pm 2.35$ & $94.36 \pm 7.87$ \\
\hline Dentistry & $24.89 \pm 1.99$ & $23.09 \pm 1.92$ & $20.63 \pm 2.73$ & $22.21 \pm 2.74$ & $91.30 . \pm 6.04$ \\
\hline Nursing \& Midwifery & $23.17 \pm 2.29$ & $21.70 \pm 3.60$ & $22.01 \pm 3.12$ & $21.84 \pm 3.01$ & $88.74 \pm 9.10$ \\
\hline Paramedical & $23.36 \pm 2.85$ & $22.00 \pm 4.15$ & $21.29 \pm 3.48$ & $22.20 \pm 3.39$ & $88.87 \pm 10.48$ \\
\hline Health & $22.73 \pm 4.15$ & $21.18 \pm 3.75$ & $21.34 \pm 3.20$ & $21.88 \pm 3.85$ & $87.14 \pm 10.69$ \\
\hline
\end{tabular}

Table 4) The mean \pm SD of psychological capital and its subscales in terms of fields of study

\begin{tabular}{lccccc}
\hline \multicolumn{1}{c}{ Field of study } & Self-efficacy & Hope & Optimism & Resiliency & Psychological capital \\
\hline Nursing & $24.31 \pm 1.70$ & $22.82 \pm 1.82$ & $24.02 \pm 2.07$ & $23.68 \pm 1.64$ & $94.85 \pm 4.18$ \\
Medicine & $26.10 \pm 3.20$ & $23.62 \pm 2.98$ & $22.84 \pm 2.62$ & $22.36 \pm 2.46$ & $94.57 \pm 8.47$ \\
Dentistry & $24.89 \pm 1.90$ & $23.57 \pm 1.92$ & $20.63 \pm 2.73$ & $22.21 \pm 2.74$ & $91.31 \pm 6.04$ \\
Medical emergency & $25.01 \pm 2.00$ & $22.00 \pm 1.12$ & $20.00 \pm 1.11$ & $23.00 \pm 1.21$ & $90.00 \pm 2.10$ \\
Laboratory sciences & $23.42 \pm 4.60$ & $22.06 \pm 3.84$ & $22.33 \pm 3.67$ & $22.69 \pm 3.20$ & $90 . .51 \pm 11.54$ \\
Public health & $21.54 \pm 3.00$ & $20.38 \pm 3.85$ & $20.90 \pm 3.26$ & $21.93 \pm 2.70$ & $84.77 \pm 10.29$ \\
Occupational health & $23.48 \pm 4.10$ & $20.56 \pm 4.50$ & $21.64 \pm 2.99$ & $21.08 \pm 3.58$ & $86.78 \pm 11.57$ \\
Environmental health & $24.33 \pm 2.40$ & $22.87 \pm 2.43$ & $21.72 \pm 3.60$ & $22.81 \pm 4.55$ & $91.75 \pm 8.90$ \\
Midwifery & $23.42 \pm 2.20$ & $21.00 \pm 5.83$ & $21.21 \pm 3.74$ & $20.64 \pm 3.45$ & $86.28 \pm 11.53$ \\
Anesthesia & $21.88 \pm 2.70$ & $21.80 \pm 3.24$ & $20.68 \pm 3.17$ & $21.04 \pm 4.21$ & $85.40 \pm 9.97$ \\
Surgical technology & $21.16 \pm 1.30$ & $21.04 \pm 0.80$ & $20.00 \pm 1.44$ & $20.50 \pm 2.62$ & $82.70 \pm 4.68$ \\
Radiology & $24.11 \pm 1.90$ & $23.69 \pm 2.41$ & $20.11 \pm 3.61$ & $22.80 \pm 1.44$ & $9073 \pm 8.10$ \\
Radiotherapy & $23.05 \pm 2.80$ & $19.40 \pm 7.31$ & $23.10 \pm 4.03$ & $22.05 \pm 5.223$ & $87.60 \pm 15.71$ \\
M.Sc. fields & $20.57 \pm 3.90$ & $21.57 \pm 2.06$ & $21.36 \pm 2.31$ & $22.00 \pm 1.56$ & $85.52 \pm 8.16$ \\
\hline
\end{tabular}

Also, there was a significant relationship between students' field of study and total score of psychological capital and its subscales $(p=0.04)$. Nursing students obtained the highest total score of psychological capital with the mean and standard deviation of $94.85 \pm 4.18$ and students of Surgical technology obtained the lowest total score of psychological capital with the mean and standard deviation of $82.70 \pm 4.68$ compared to other students (Table 4).

\section{Discussion}

The aim of the research was to study the psychological capital of students in Kurdistan University of Medical Sciences in 2016. The mean psychological capital of students was 89.09 \pm 9.98 . The mean psychological capital of students was above average, which is in agreement with a research carried out by Sangatash et al. [14]. Among the components of psychological capital, the highest score was associated with self-efficacy with mean score Health Education and Health Promotion of $23.48 \pm 3.29$ and the lowest score was associated with optimism with mean score of 21.63 \pm 3.22 . There was a significant relationship between sex and psychological capital $(p \leq 0.05)$. The total score of psychological capital in male students was more than that of female students. The result was consistent with Liogsky's study [15]. The culture of society is important in this regard because it allows men to try their best on their favorite fields; thus, they have high selfefficacy and hope. On the other hand, they are very resilient against problems due to their masculine features, leading to the increasing psychological capital in men. But, such background is not provided for women due to the constraints of society. In addition, the results of data analysis showed that there was a significant relationship between academic degree of students and psychological capital $(p<0.05)$. Such result is consistent with the results of studies performed by Simon and Buitendach as well as Imani and Mohajeran [16, 17]. The highest mean was obtained for Ph.D. 
candidates. Regarding such significant difference, the education is effective on individuals' attitude and life. Individuals with different educations have various attitudes towards the life. On the other hand, they know themselves due to their educations; hence, they experience higher self-concept and selfefficacy. In some cases, they have jobs, social position with high hope, and optimism due to higher education, leading to the increasing psychological capital in such people.

There was a significant relationship between the students' field of study and psychological capital $(\mathrm{p}<0.05)$. Such result is consistent with a study conducted by Rezaei et al. [18]. To explore this relationship, the field of study determines the future of students. The fields of study, for which the job market is promising, are more optimistic and hopeful. Such optimism and hope increase their selfefficacy as well as their tolerance against difficulties and resiliency. Moreover, there is a significant relationship between faculty place of students and psychological capital $(\mathrm{p}<0.05)$. Paramedical students and health students obtained the highest and the lowest means, respectively. Such result is in agreement with the results of Simon and Buitendach's study [16]. There was no significant relationship between marital status, age, and psychological capital. This is in agreement with the results of studies conducted by Simon et al. as well as Rahimi et al. [16, 19]. It means students of Kurdistan University of Medical Sciences believed these two variables were ineffective on psychological capital.

Since mean psychological capital of female students is low, it is suggested that essential measures be taken to increase their psychological capital. In addition, concerning the significant relationship of academic degree, the rate of hope and optimism of students, their psychological capital can be increased by providing jobs for students in different fields.

The limitations of this study are that it is a self-report and students may not have completed the questionnaires with sufficient accuracy.

\section{Conclusion}

Factors such as sex, field of study, academic degree, and faculty place are effective in the psychological capital of students.

Acknowledgements: The authors would like to thank all students who collaborated in the project as well as completed and delivered the questionnaires. Furthermore, the authors would like to thank the student research committee of Kurdistan University of Medical Sciences due to the approval of the project and financial supports.

Ethical permissions: No ethical approval code was reported by the authors.

Conflict of Interests: The authors declare that there is no conflict of interest.

Authors' Contribution: Rezaei Z. (First author), Introduction author/ Methodologist/ Statistical analyst/ Discussion author (20\%); Vahabi A. (Second author), Introduction author/ Methodologist/ Discussion author (15\%); Karimianpour Gh. (Third author), Introduction author/ Methodologist/ Statistical analyst/ Discussion author (20\%); Latifi A (Fourth author), Assistant (5\%); Ramezani Sh (fifth author), Introduction author/ Original researcher/ Discussion author (10\%); Nouri E. (sixth author), Introduction author/ Original researcher/ Discussion author (10\%); Moradi M. (seventh author), Introduction author/ Methodologist/ Statistical analyst/ Discussion author (20\%)

Funding: The costs of research project with grant No. 95/66 were paid by the assistance of research and technology of Kurdistan University of Medical Sciences in 2016.

\section{References}

1- Hoveida R, Mokhtari H, Forohar M. The relationship between psychological capital and organizational commitment components. Res Cogn Behav Sci. 2013;2(2):43-56. [Persian]

2- Forohar M, Hoveida R. Psychological capital and intraprunership among faculty members. Cult Counsel. 2012;2(8):83-100. [Persian]

3- Seligman MEP, Csikszentmihalyi M. Positive psychology: An introduction. Am Psychol. 2000;55(1):514.

4- Luthans F, Avey JB, Avolio BJ, Norman SM, Combs GM. Psychological capital development: Toward a microintervention. J Organ Behav. 2006;27(3):387-93.

5- Luthans F, Youssef CM. Emerging positive organizational behavior. J Manag. 2007;33(3):321-49.

6- Judge TA, Bono JE. Relationship of core selfevaluations traits--self-esteem, generalized self-efficacy, locus of control, and emotional stability--with job satisfaction and job performance: A meta-analysis. J Appl Psychol. 2001;86(1):80-92. 
7- Bandura A. Self-efficacy: Toward a unifying theory of behavioralchange.AdvBehavResTher.1978;1(4):139-61. 8- Bailey TC, Eng W, Frisch MB, Snyder CR. Hope and optimism as related to life satisfaction. J Posit Psychol. 2007;2(3):168-75.

9- Seligman MEP. Learned optimism: How to change your mind and your life. New York: Pocket Books; 1998. 10- Stewart M, Reid G, Mangham C. Fostering children's resilience. J Pediatr Nurs. 1997;12(1):21-31.

11- Masten AS, Obradovic J. Competence and resilience in development. Ann N Y Acad Sci. 2006;1094:13-27.

12- Mohebbi Noorodinvand MH, Shehni Yeilagh M, Sharifi HP. The relationship of psychological capital (hope, optimism, resiliency and self-efficacy) with the achievement goals and academic performance of the first-year students. Curric Plan Knowl Res Educ Sci. 2014;11(13):61-79. [Persian]

13- Shakarami M, Davarnia R, Zahrakar K. Predictor factors of psychological well-being in students. J Sabzevar Univ Med Sci. 2014;21(3):68-481. [Persian]

14- Ghane Sang-Atash A, Mirzazadeh ZS, Azimzadeh SM, Abdolmaleki $\mathrm{H}$. The role of psychological capital on social capital of physical education students of Mashhad universities. Appl Res Sport Manag Biol. 2015;4(15):91106. [Persian]
15- Heitler Lehoczky M. The socio-demographic correlations of psychological capital. Eur Sci J. 2013;9(29):26-42.

16- Simons JC, Buitendach JH. Psychological capital, work engagement and organisational commitment amongst call centre employees in South Africa. SA J Indust Psychol. 2013;39(2):1-12.

17- Imani M, Mohajeran B. The relationship between psychological capital and spiritual intelligence with vitality of Urmia University students. National Conference on Psychology of Educational and Social Sciences; 2015. Mazandaran: Kome Scientific Research Institute of Elm Avaran Danesh; 2015. [Persian]

18- Rezaei Jondaani M, Hoveida R, Samavatiyan H. Investigating the relationship between demographic characteristics and psychological capital of teachers (Case study: Primary school teachers in Isfahan city). First National Conference on Psychology and Educational Scienses; 2014. Marvdasht: Institute of Andishesazan-e Mobtaker-e Javan. [Persian]

19- Rahimi F, Oreyzi HR, Nouri A, Namdari K. The relationship between psychological capital in personnel work setting with their work flow and engagement in the organization. Q J Career Organ Couns. 2012;4(12):930. [Persian] 